\title{
Diáspora, refugiado, migrante: perspectiva etnográfica em mobilidade e transfronteiriça
}

\author{
Handerson Joseph \\ Professor Doutor da Universidade Federal do Amapá, \\ Brasil e da Université d’État d'Haiti, Haiti \\ handersonj_82@yahoo.es
}

Resumo Este artigo propõe uma discussão sobre a maneira pela qual as categorias diáspora, migrante e refugiado são, mutuamente, constituídas no mundo social haitiano, a partir da experiência etnográfica em mobilidade e múltiplos engajamentos do pesquisador em campo. Pergunta-se então:quais são os sentidos sociais e pragmáticos atribuídos pelos haitianos às categorias de diáspora, refugiado e migrante? De que modo a mobilidade se torna um conceito chave para pensar as dinâmicas do ser diáspora, refugiado e migrante no espaço (trans)nacional e (trans)fronteiriço?. O foco é o contingente de haitianos vindos ao Brasil pela fronteira entre Brasil, Colômbia e Peru, de 2010 a 2013 e os que foram para o Suriname e a Guiana Francesa neste mesmo período. A pesquisa etnográfica articula-se a partir da referida fronteira, mas desenvolve-se também em Manaus (Brasil), Caiena (Guiana Francesa), Paramaribo (Suriname) e Fonds-des-Nègres e Pemerle (Haiti).

Palavras-chave: Diáspora, refugiado, migrante, etnografia em mobilidade, (trans)fronteiriço.

Quando alcancei a fronteira - Brasil, Colômbia e Peru -, em janeiro de 2012, havia aproximadamente dois mil haitianos no local e já eram passados dois anos desde a vinda deles por esse circuito. Inicialmente, interessavame saber como se constituíra a chegada dos primeiros à região, para melhor compreender a dinâmica e a lógica da sua mobilidade nessa fronteira. Os meus interlocutores haitianos com mais tempo no local (desde algumas semanas até três meses), aguardavam o protocolo para seguir viagem em direção a Manaus, a outros estados brasileiros ou territórios, notadamente à Guiana francesa. 
Nas conversas iniciais com os coordenadores da Pastoral da Mobilidade Humana em Tabatinga ${ }^{1}$ : Irmã Patrizia, italiana, da Congregação das Irmãs Missionárias de São Carlos Borromeo, Scalabrinianas, em janeiro de 2012 havia completado seis anos no local; assim como Padre Gonzalo, colombiano, pároco da Igreja Divino Espírito Santo, visualizava, de forma mais clara, o contexto da situação dos primeiros haitianos para ali vindos, relatada a seguir.

Na segunda semana de fevereiro de 2010, chegara um primeiro grupo de 12 haitianos: quatro mulheres (duas jovens de 16 e 17 anos) e oito homens pedindo ajuda. A população local já conhecia o trabalho da Pastoral e, quando eles aportaram, após passarem pelo Peru, querendo ser acolhidos, as pessoas disseram: "Aqui quem acolhe os migrantes e refugiados é Padre Gonzalo". Este entrou, então, em contato com o Alto Comissariado das Nações Unidas (ACNUR) sediado em Brasília, informando a presença de alguns haitianos na cidade pedindo refúgio e recebera orientação para levá-los à Polícia Federal (PF), com o intuito de iniciar os procedimentos burocráticos ${ }^{2}$.

Lá os haitianos fizeram entrevistas, receberam o "protocolo"- documento legalizador da situação estrangeira no país -, no qual se mencionava solicitação de refúgio. Depois de eles terem recebido o documento, os coordenadores da Pastoral da Mobilidade Humana em Tabatinga ligaram para os membros do Serviço da Pastoral do Migrante em Manaus, particularmente para os Padres da Igreja São Geraldo, e os encaminharam de barco.

Uma semana depois da chegada desses primeiros, vieram mais 20, após, 30, e assim, em maio de 2010, 150 haitianos moravam em Tabatinga. De acordo com o Padre Gonzalo, quando alcançaram esse número (em maio de 2010), a ACNUR declarou: "Padre, não podemos dar-lhes documentos de refugiados. Eles não são refugiados, então, eles não entram na nossa ajuda humanitária”.

Os agentes estatais não esperavam um número tão expressivo, pois a vinda dos primeiros era considerada um caso isolado. Como os haitianos diziam para os agentes da Pastoral que a sua intenção era ir à Guiana Francesa, então, era pouco provável imaginar que, em tão pouco tempo, a região se tornaria uma porta de entrada para a futura instalação de uma comunidade haitiana tão expressiva no Brasil. Atualmente, seriam 80

1 Em 2005, foi criada a Pastoral da Mobilidade Humana na fronteira Brasil, Colômbia e Peru, a partir de uma parceria entre três Igrejas fronteiriças localizadas cada uma num desses países. Até então, antes da chegada dos haitianos, as ações da Pastoral na fronteira eram voltadas à questão dos fluxos migratórios na região entre peruanos, colombianos, brasileiros e pessoas vindas de outros lugares do mundo, particularmente do continente africano. Entre outras ações, fora criada uma casa de acolhida, além dos atendimentos aos carcerários de diferentes nacionalidades.

2 Nos trabalhos de Rosa Vieira (2014, p. 20), Marília Pimentel e Geraldo Cotinguiba (2014, p. 78) aparece o primeiro registro, em 14 de março de 2010, dos primeiros haitianos chegados pelo Mato Grosso do Sul (MS), fronteira com a Bolívia. Então, a vinda dos haitianos em fevereiro de 2010 pela fronteira Brasil, Colômbia e Peru, particularmente em Tabatinga, é um pouco anterior ao registro de Mato Grosso do Sul. 
mil haitianos registrados pelo Ministério de Justiça. Isso não quer dizer que todo esse contingente esteja no país ${ }^{3}$.

Durante o trabalho de campo em 2012, na referida fronteira entre o Brasil, a Colômbia e o Peru, e em 2013 no Haiti, pude ver e sentir quanto o termo dyaspora (diáspora) faz parte do vocabulário social haitiano. O referido termo se generalizou, transformandose num conceito que serve no cotidiano como substantivo e adjetivo para designar e qualificar pessoas, objetos, dinheiro, casas e ações, como nas expressões "Diáspora, como você vai?" (Dyaspora, ki jan ou ye?), "Isso é roupa diáspora" (Sa se rad dyaspora), "Tenho dinheiro diáspora" (Mwen gen lajan dyaspora), "Essa é uma casa diáspora" (Sa se yon kay dyaspora), "Você age como diáspora" (Ou aji tankou dyaspora), "Você não é qualquer um, é uma pessoa diáspora" (Ou pa nenpòt ki, ou se yon moun dyaspora), entre outras (Joseph, 2015a, 2015b, 2017a, 2017b e 2017c).

Pergunta-se então: quais são os sentidos sociais e pragmáticos atribuídos pelos haitianos às categorias de diáspora, refugiado e migrante? De que modo a mobilidade se torna um conceito chave para pensar as dinâmicas do ser diáspora, refugiado e migrante no espaço (trans)nacional haitiano e transfronteiriço?. Partindo dessas perguntas chaves, este artigo tem por objetivo examinar a maneira pela qual as categorias diáspora, refugiado e migrante são, mutuamente, constituídas no mundo social haitiano, um universo cada vez mais globalizado e em rede. Desta forma, ao tomar como foco essas duas indagações, foi preciso lançar mão da etnografia em mobilidade, e de múltiplos engajamentos, permitindo captar as imbricações e as relações entre as pessoas em movimento, a circulação em diferentes espaços nacionais e transnacionais, espaços fronteiriços e transfronteiriços.

O modelo etnográfico em mobilidade ou etnografia móvel, segundo Marcus (2001), além de permitir apreender as trajetórias, as rotas e os circuitos dos sujeitos da pesquisa em diferentes espaços sociais, permite compreender as suas práticas sociais, isto é, a maneira pela qual os próprios sujeitos em mobilidade agem nesses locais, mudando a paisagem na medida em que transformam a si mesmos; dando sentido aos espaços; utilizando novos mecanismos para facilitar a sua circulação frente às barreiras e aos controles dos governos por onde passam ou ficam. Nessa mesma direção, em Mobile Methods, Monika Büscher, John Urry e Katian Witchger (2011) propõem uma etnografia móvel, argumentando que o pesquisador deve levar em conta os movimentos itinerantes de pessoas e objetos.

O foco da pesquisa é o contingente vindo ao Brasil pela fronteira com a Colômbia e o Peru de 2010 a 2013, e quem fora para o Suriname e a Guiana Francesa neste mesmo período. $\mathrm{O}$ trabalho de campo se concentrou, numa primeira etapa, na referida fronteira e em Manaus, entre janeiro e março de 2012; numa segunda, no Suriname (Paramaribo)

3 Ver <http://www.brasil.gov.br/cidadania-e-justica/2016/09/governo-prorroga-visto-humanitario-para-haitianos $>$. Acesso em: 18 set. 2016. Os dados devem ser problematizados porque é complexo afirmar números bem definidos, visto ser quase impossível mensurar o mundo em movimento.Além de, possivelmente, nem todos os imigrantes terem passado pela Polícia Federal brasileira ou enviado os seus dados para o Conselho Nacional de Imigração (CNIg). 
e na Guiana Francesa (Cayenne), de março a maio de 2013; e numa terceira, no Haiti (Fonds-des-Nègres e Pemerle), em julho desse mesmo ano.

No tangente aos idiomas utilizados em campo, durante as três fases da pesquisa, foram créole e francês na interação com os haitianos; português com os brasileiros; espanhol com os peruanos e os colombianos; francês com os guianenses e os franceses de Paris.

\section{Refugiados, migrantes}

Desde fevereiro de 2010, o protocolo recebido na Polícia Federal (PF) pelos haitianos que chegaram às fronteiras brasileiras sem visto exigido pelo Governo do país, mencionava a solicitação de refúgio, mas, a partir de maio do mesmo ano, não eram considerados refugiados ${ }^{4}$. A fim de criar um novo dispositivo legal para acolher os haitianos vindos ao Brasil sem os vistos exigidos, o Governo brasileiro, por meio do Conselho Nacional de Imigração - CNIg -, promulgou, em 12 de janeiro, a Resolução Normativa n 97/2012, criando um visto humanitário até então não existente na legislação brasileira. Inicialmente, a Resolução permitia duas leituras: a produção de uma possibilidade de legalização dos haitianos no país e, ao mesmo tempo, a restrição da chegada de novos migrantes.

Se os imigrantes que chegaram de fevereiro até junho de 2010 eram considerados refugiados, a partir de meados do referido ano, do ponto de vista do Governo brasileiro, os novos eram tratados burocrática e juridicamente nos seguintes termos do novo documento criado para tanto, a seguir apresentado:

Dispõe sobre a concessão do visto permanente previsto no art. 16 da Lei $\mathrm{n}^{\circ}$ 6.815, de 19 de agosto de 1980, a nacionais do Haiti. O CONSELHO NACIONAL DE IMIGRAÇÃO, instituído pela Lei no 6.815, de 19 de agosto de1980 e organizado pela Lei $n^{\circ} 10.683$, de 28 de maio de 2003, no

4 Os primeiros haitianos desembarcados não pediam visto na Embaixada brasileira no Haiti para ingressar no Brasil. Mas, para passar pelo Brasil e ir ao Departamento ultramarino era necessário ter visto brasileiro, e também, para aqueles que desejavam ficar no país. Foi a partir dessas experiências que começaram os primeiros questionamentos dos agentes do Governo de como poderiam proceder para criar um novo dispositivo legal para receber os haitianos, não na condição de refugiados, porque CONARE e ACNUR já diziam não serem considerados refugiados, de acordo com o conteúdo da Convenção de Genebra de 1951. Nessa época, até a presente data, para receber um visto de residência no Brasil, o candidato deveria cumprir certos requisitos: ser cônjuge de um cidadão brasileiro ou residente permanente no Brasil; ou ser membro imediato (dependente) da família de um cidadão brasileiro ou residente permanente no Brasil. Os haitianos vindos na época não se enquadravam nesses requisitos. Com a Resolução n ${ }^{\circ}$ 97/2012, o Governo simplificou a forma de acesso dos haitianos a um visto permanente no Brasil, e aumentaram significativamente os pedidos na Embaixada brasileira no Haiti. Por conseguinte, o processo de análise da documentação e da entrega dos vistos começou a demorar mais tempo do que antes de 2011 e 2012. Isso, de alguma forma, contribuiu para os novos candidatos optarem por realizar viagens clandestinas até as fronteiras brasileiras, particularmente no norte do país e, consequentemente, solicitar o visto permanente brasileiro nos estabelecimentos da Polícia Federal nos municípios fronteiriços e não na Embaixada brasileira no Haiti, pois o processo demora atualmente entre cinco a oito meses para análise e recebimento do visto. 
uso das atribuições que lhe confere o Decreto $n^{\circ} 840$, de 22 de junho de 1993, resolve:

Art. $1^{\circ}$ - Ao nacional do Haiti poderá ser concedido o visto permanente previsto no art. 16 da Lei $\mathrm{n}^{\circ}$ 6.815, de 19 de agosto de 1980, por razões humanitárias, condicionado ao prazo de 5 (cinco) anos, nos termos do art. 18 da mesma Lei, circunstância que constará da Cédula de Identidade do Estrangeiro.

Parágrafo único. Consideram-se razões humanitárias, para efeito desta Resolução Normativa, aquelas resultantes do agravamento das condições de vida da população haitiana em decorrência do terremoto ocorrido naquele país em 12 de janeiro de 2010.

Art. $2^{\circ}-\mathrm{O}$ visto disciplinado por esta Resolução Normativa tem caráter especial e será concedido pelo Ministério das Relações Exteriores, por intermédio da Embaixada do Brasil em Porto Príncipe.

Parágrafo único. Poderão ser concedidos até 1.200 (mil e duzentos) vistos por ano, correspondendo a uma média de 100 (cem) concessões por mês, sem prejuízo das demais modalidades de vistos previstas nas disposições legais do País.

Art. $3^{\circ}$ - Antes do término do prazo previsto no caput do art. $1^{\circ}$ desta Resolução Normativa, o nacional do Haiti deverá comprovar sua situação laboral para fins da convalidação da permanência no Brasil e expedição de nova Cédula de Identidade de Estrangeiro, conforme legislação em vigor.

Art. $4^{\circ}$ - Esta Resolução Normativa vigorará pelo prazo de 2 (dois) anos, podendo ser prorrogada.

Art. $5^{\circ}$ - Esta Resolução Normativa entra em vigor na data de sua publicação (Conselho Superior da Justiça do Trabalho, 2012, p. 1-4).

É interessante observar a maneira pela qual as categorias "refugiados" e "migrantes" foram mobilizadas pelo Governo para enquadrar juridicamente ou não os haitianos nas políticas migratórias brasileiras. Dessa forma, criou-se uma nova categoria jurídica. Para usar a expressão de Michel Foucault (2008), constitui-se uma espécie de "governamentalidade" ou modo de "governar" a mobilidade haitiana. Inicialmente, houve a "criação de modelos padronizados sobre a mobilidade haitiana", o que tenderia a produzir uma "categoria de gestão" para referir-se aos haitianos (Vieira, 2017, p. 230).

Numa perspectiva etnográfica, boa parte dos interlocutores haitianos quase não se autoidentificavam como refugiados ou migrantes. Há diferença entre os pontos de vista do Governo sobre os pontos de vista dos haitianos e os pontos de vista deles mesmos. São muitos pontos de vista, sentimentos e relações ambíguas com o universo da mobilidade.

Para as pessoas em mobilidade, as questões legais são estratégicas, pensadas, calculadas, mas, às vezes, também inesperadas e sofridas nos trajetos de acordo com as políticas restritivas dos governos. É preciso saber circular entre mundos legais, mantendo uma 
relação digna e produtiva com o Haiti, tal como se disse no universo haitiano: chèche lavi, buscando ou tentando levar a vida e o bem-estar, seja juntando dinheiro, cumprindo as obrigações com os que ficam, mantendo reputações pessoais e familiares, ou tendo acesso ao documento de visto de residência no Brasil, pois são várias questões em jogo.

Dessa forma, chegar à Guiana Francesa tem um sentido específico que dá acesso aos documentos dos territórios franceses para, posteriormente, alcançar a França ou outros países, chamados peyi blan, referindo-se àqueles desenvolvidos socioeconomicamente França, Estados Unidos e Canadá -, nos quais se ganha em euro, dólar americano ou canadense, denominados lajan dyaspora (dinheiro diáspora). Quando estes viajantes voltam ao Haiti, eles mesmos se autodesignam e são denominados pelos que ficaram no país de dyaspora ou diaspora (diáspora). Dentre eles, alguns exibem o sucesso da viagem através da construção de casas também chamadas de kay dyaspora (casas diáspora) e nelas há objetos trazidos dos países de residência que são chamados bagay dyaspora (objetos diásporas).

Num outro plano, no universo haitiano, particularmente no Haiti, o termo refugiado, em créole refijye, está associado aos boat people, referindo-se aos compatriotas que viajavam desde as décadas de 1970 clandestinamente para os Estados Unidos, particularmente Miami, em embarcações precárias. Muitos deles foram interceptados em alto mar e conduzidos ao campo de Guantânamo, onde permaneceram alguns meses ou anos. Outros perderam a vida pelo fato da embarcação ter naufragado espontaneamente ou provocado pelos agentes estadunidenses. Nesse sentido, ser refugiado possui uma conotação pejorativa no universo haitiano. Geralmente não é considerada uma pessoa com valor moral e prestígio social, por isso, algumas pessoas se sentem incomodadas ao serem identificadas como refugiadas, porque dá a ideia de serem fugitivas (mawon ou marron) ${ }^{5}$, e isso, do ponto de vista deles, fere o seu orgulho e sua honra diante da sociedade, diferentemente do uso do termo diáspora que serve como substantivo e adjetivo para designar e qualificar o migrante haitiano residente no exterior que volta temporariamente ao Haiti, exibindo dinheiro e

5 Marronnage vem da palavra espanhola cimarronada e refere-se ao fenômeno iniciado no regime colonial quando os africanos e seus descendentes escravizados na Ilha São Domingo fugiam dos trabalhos forçados e das condições dramáticas impostas pelo sistema colonial. Os fugitivos eram denominados de marron ou nèg mawon (negro fugitivo). Até os dias atuais no Haiti se usa a palavra marron para os haitianos que estão fugindo em escala regional ou (trans)nacional por alguma situação associada à política, ao jurídico, à feitiçaria do vodu, às brigas entre familiares e amigos. As pessoas costumam dizer: Entèl nan mawon, fulano está fugindo, ou Entèl nan kache, fulano está se escondendo. A palavra marronnage está articulada à mobilidade das pessoas, isto é, ao deslocamento de um lugar para outro e também associada ao conceito de diáspora. Nem sempre as pessoas acusadas de marron se consideram como tal, por mais que, de fato, possam estar no marronnage pelas razões evidenciadas, entre outras. Se a pessoa está em outro país, como República Dominicana, quando volta ao Haiti, para as pessoas que ficaram e não a haviam visto durante o tempo de marronnage, ela pode ser chamada de diáspora pelo fato de ter ido residir em outro país por um tempo e depois voltado ao Haiti. No entanto, isso deve ser nuançado, porque, quando as pessoas sabem que o motivo da viagem é para se esconder em outro território, ele estava no marronnage, deixando de ser considerado e chamado de diáspora. Assim como o termo "refugiado" possui conotação ambígua e pejorativa, no Haiti, os termos marronnage e marron também são ambíguos e possuem suas nuances. 
objetos, demonstrando o sucesso da viagem. Geralmente, boa parte dos haitianos gosta de ser chamado e de se autodesignar como diáspora e não como refugiado, a não ser por estar de fato numa situação de refúgio ou por questões burocráticas e jurídicas das políticas migratórias em outros países.

\section{Diáspora}

Pergunta-se então: de qual modo o termo diáspora revela formas de regular os relacionamentos entre os que partem e os que ficam, entre os que estão e os que chegam e os que viajam e voltam? Como tantos outros haitianos vivendo num universo de forte tradição de mobilidade em escala local, regional e (trans)nacional, desde a adolescência, o jovem Henri tinha o sonho de ir aos Estados Unidos, mas na época não havia sido possível e decidiu dirigir-se para a República Dominicana, onde vivia com seu pai. Ele não pensava em outra coisa além de partir. E essa intenção não era exclusiva dele, o universo haitiano trata de um mundo em mobilidade que é a perspectiva do horizonte de boa parte da população.

Conheci Henri por ocasião da pesquisa de campo na Guiana Francesa. Nascido em 1985, na cidade de Jacmel, no sul do Haiti, possuía um irmão menor residente em sua cidade natal com a mãe e o pai morava na República Dominicana. Estudou até o terceiro ano do ensino médio (quatrième secondaire) no Haiti e depois foi continuar os estudos em Santo Domingo. Antes da viagem, ainda em Jacmel, Henri tinha muitos amigos com familiares aletranje (no exterior) e ele também possuía tios e tias residentes nas cidades americanas Brooklyn, Nova Jersey e Miami.

Durante os seus estudos na adolescência, era frequente alguns dos seus colegas chegarem à escola e dizerem:"Estou indo embora, amigo, recebi o meu visto de residência permanente (chamado pelos haitianos de rezidans)". O clima era mais ou menos assim durante o segundo e o terceiro ano do ensino médio: vários dos seus colegas de turma partiam ao longo do ano acadêmico.

Foi nesse contexto que cresceu a sua intenção de partir, rumando ao exterior. Para ele, era uma questão moral e de honra. Nas suas palavras: "Se eu ficasse no Haiti, iria sentir-me mal, porque tinha muitos colegas aletranje. Daí pensei: tenho de partir também, mesmo que não seja para Miami”. Em 2003, ligou para seu pai residente na República Dominicana e lhe disse: "Se puder voye chèche'm (me manda buscar) para finalizar os estudos na República Dominicana”. O pai financiou a sua viagem de ônibus até Santo Domingo. Ingressou num colégio, mas, um ano depois desistiu. Resolveu fazer um curso técnico de pintura. Logo em seguida começou a trabalhar, a ganhar seu próprio dinheiro com a pintura e retomou a sua ideia inicial de ir a Miami.

Estando em Santo Domingo, ele queria ir à Ilha de Dominica (ou Comunidade de Dominica, localizada próximo a Guadalupe e Martinica) para depois alcançar a cidade americana de Miami. Na época, quem tinha Cédula (carteira de identidade) de um ano da 
República Dominicana podia ficar dois meses no país. Infelizmente, Henri foi demitido do supermercado onde trabalhava em Santo Domingo e acabou usando para o seu sustento o dinheiro que juntava para realizar a viagem à Ilha de Dominica.

Em 2010, depois do terremoto no Haiti, estando em Santo Domingo, ele soube por um compatriota haitiano que não era preciso ter visto para ir ao Equador. Muitos iam àquele país para alcançar outros países como Chile, Venezuela, Argentina, Brasil e Guiana Francesa. Decidiu aventurar-se, comprou passagem e, junto com um primo, rumou ao Equador. Quando chegou a esse último país, conheceu alguns compatriotas residentes há alguns anos no Equador que iam para o Peru e, posteriormente, alcançavam a fronteira entre Brasil, Colômbia e Peru. Henri e seu primo fizeram o mesmo trajeto até chegar à Tabatinga. Permaneceu um período de três meses na fronteira, aguardando o protocolo, alojando-se na Igreja Divino Espírito Santo em Tabatinga, o local de funcionamento da Pastoral da Mobilidade.

Nessa ocasião, sua esposa ficou em Santo Domingo com seu filho de três anos que veio a falecer por conta de uma doença, quando Henri já estava em Tabatinga. Após receber o protocolo, foi a Manaus, onde permaneceu por 15 dias. Nesse local, um dia, Henri estava em Lakay (minha ou nossa casa) - assim era chamada pelos haitianos a Igreja São Geraldo em Manaus -, jogando dominó com os amigos na frente do salão paroquial da Igreja, quando um conterrâneo chegou e disse:"Gente, vamos para Guiana”. No mesmo dia, Henri arrumou as poucas roupas que trouxera para a viagem e, junto com dois compatriotas, pegou um barco para Santarém e de lá para Macapá, seguindo em ônibus até Oiapoque; atravessaram de balsa para a Comuna Saint Georges na Guiana, rumando à Cayenne. Segundo ele:

A minha intenção (desde a República Dominicana) era ir à Guiana, de lá para o Suriname, estando lá queria alcançar São Tomás (Ilhas Virgens Americanas). De São Tomás seria mais fácil alcançar Estados Unidos. O meu sonho é ser diáspora. Desde que era criança queria ir a Miami, Equador não era meu destino, Brasil não era meu destino. Todos esses lugares pelos quais passei e cheguei, eram caminhos que buscava, um couloir (corredor). Por isso, queria atravessar país por país, porque me lembro na época que morava no Haiti, em Jacmel, a maioria das pessoas ia para o Suriname para depois chegar aqui (Guiana Francesa). Alguns diziam que, no Suriname, conseguiam a documentação, iam para Holanda e de lá percorriam outros países. Era a época em que o Suriname estava sob o domínio dos holandeses (Henri, maio de 2013, Cogneau Lamirande/Guiana Francesa).

Mesmo estando na Guiana, trabalhando informalmente, vendendo borlette ${ }^{6}$ para um patrão haitiano e ter alugado uma casa em Cogneau Lamirande na Comuna de Matoury, ele continuava com a ideia inicial de ir a Miami: "Fòk mwen konnen Miami yon jou" (Devo conhecer Miami um dia). Em maio de 2013, quando o encontrei em Cogneau 
Lamirande, residia com a sua esposa, pois ele financiara a viagem dela. Na época, ela estava grávida de seis meses.

A trajetória de Henri revela parte da geografia da mobilidade haitiana, a partir da hierarquização dos destinos articulada aos sentidos que ela possui para os haitianos no Haiti e no exterior. Aqui utilizo trajetória "como série de posições sucessivamente ocupadas por um mesmo agente (ou um mesmo grupo) num espaço que é, ele próprio, um devir, estando sujeito a incessantes transformações” (Bourdieu, 1986, p. 71).

Para Henri, Estados Unidos e França continuavam sendo os destinos privilegiados para ser uma pessoa diáspora, ter lajan diaspora (dinheiro diáspora) e quem sabe, ter a oportunidade de construir kay diaspora (casa diáspora). Inúmeros jovens como Henri passam a adolescência e a juventude com a perspectiva e a esperança de um dia conhecer peyi Bondye (o país de Deus), isto é, os Estados Unidos, o que torna a mobilidade constitutiva dos horizontes de possibilidades deles.

\section{Mobilidade}

A abordagem proposta aqui possui a sua peculiaridade. Estes sujeitos diaspóricos em mobilidade rompem com a lógica de emigrantes e imigrantes como, por exemplo, aqueles que saem de um lugar $\mathrm{X}$ de origem para ir a um lugar $\mathrm{Y}$ de destino. Não há apenas um movimento unidirecional de um lugar de saída (Haiti) para outro de destino (Brasil ou Guiana Francesa). Eles não se movem simplesmente entre dois lugares, mas circulam entre vários, constituindo uma "multipolaridade da migração", caracterizando os diferentes polos dela e a "interpolaridade das relações” (Ma Mung, 1992, p. 187). Seus sonhos e suas vidas cruzam as fronteiras nacionais. Por isso, devem ser compreendidos na equação de pessoas em mobilidade que circulam entre os diferentes pólos da mobilidade internacional. Desta forma, torna-se crucial a etnografia em mobilidade para acompanhar a circulação das pessoas.

Desde a década de 1970, Abdelmalek Sayad já havia alertado nos seus trabalhos que, "na origem da imigração encontramos a emigração, ato inicial do processo, mas igualmente necessidade de ordem epistemológica [...]; como duas faces de uma mesma realidade, a emigração fica como a outra vertente da imigração..." (1998, p. 14). Por isto, torna-se importante estudar as diferentes interfaces do ato de migrar, da circulação e não apenas de uma parte desse ato, a emigração ou a imigração. Nesse sentido, a mobilidade se torna uma das palavras-chaves centrais para compreender essa dinâmica circulatória.

Nesta perspectiva,é mais o sujeito em mobilidade e em circulação do que o emigrante ou imigrante que está no coração da análise (Simon, 1981, 1992; Tarrius, 2000; Doraï et al., 1998). O acento cai mais sobre as dinâmicas, as lógicas e as relações sociais construídas durante o percurso da viagem do que os determinantes da migração. Em tal contexto, a pesquisa se situa mais a partir do paradigma dos territórios circulatórios (Tarrius, 2000) do que na integração das pessoas nos lugares de chegada e de instalação. 
Itinerários e circuitos são cada vez mais complexos e mundializados e, a partir deles, surgem novas rotas imprevisíveis e inéditas como é o caso do Brasil, nas novas configurações da mobilidade haitiana. Segundo Alain Tarrius, "os territórios circulatórios compreendem as redes definidas pelas mobilidades de populações que possuem o seu status de saber-circular" (2000, p. 124). Ele explica que "a noção de território circulatório constata a socialização de espaços que, como se refere, seguem as lógicas de mobilidades" (Tarrius, 2000, p. 124 - 125). O conceito território circulatório traz a sua contribuição à problemática complexa das formações espaciais e sociais associadas à mobilidade. Como oportunamente refere Karen Fog Olwig: "As migrações dizem mais acerca do papel ocupado pelos lugares, destinos e percursos na vida das pessoas do que acerca de processos de integração" (2007, p. 21).

Estou de acordo com Federico Neiburg, quando o autor afirma: "Mais do que a noção de emigração [...] é a noção de mobilidade que permite descrever essa itinerância que molda as vidas haitianas, colapsando as escalas local, nacional e transnacional num único espaço social pelo qual transitam pessoas, moedas e mercadorias" (Neiburg, 2016, p. 8).

É complexo abordar etnograficamente a mobilidade haitiana, permanecendo o etnógrafo num único lugar. Por isso, foi importante, nesta pesquisa, lançar mão de uma perspectiva metodológica que desse conta da exigência do objeto dessa investigação. Para os etnógrafos interessados na mobilidade de pessoas, a etnografia em mobilidade permite explorar situações múltiplas em espaços sociais diferentes, bem como seguir as pessoas, acompanhando as experiências vividas, descrevendo a trajetória de vida delas "como um caminho, uma estrada, uma carreira, com suas encruzilhadas" (Bourdieu, 1986, p. 69).

\section{Etnografia em mobilidade}

Como analisado no início deste texto, durante o trabalho de campo em Tabatinga, boa parte dos interlocutores me diziam que estavam indo para a Guiana Francesa. É possível observar isso na trajetória de Henri, que ficou temporariamente no Brasil e depois foi à Guiana.

Essas narrativas muito contribuíram para eu seguir os rumos da pesquisa à Guiana, em março de 2013. Nesse Departamento ultramarino francês, observei que antes de 2010, os haitianos passavam pelo Suriname para chegar à Cayenne. Segundo os meus interlocutores, em 2009, o Governo francês, sob o comando do Presidente Nicolas Sarkozy (mandato 2007-2012) solicitou ao Suriname diminuir os vistos concedidos aos haitianos para controlar a entrada destes na Guiana. A partir do momento em que "fechou o Suriname" (Sirinam fèmen) - expressão utilizada pelos haitianos -, começaram a se criar outras redes, rotas, e circuitos se "abriram" para chegar ao Departamento francês. Nesse contexto, deve-se situar a chegada, em janeiro de 2010, de centenas de haitianos à fronteira Brasil, Colômbia e Peru. 
Num outro plano, em julho de 2013, a minha decisão para ir ao Haiti e continuar o trabalho de campo foi articulada quando estava na Guiana Francesa e observei que os primeiros haitianos chegados na década de 1960 e a maioria dos que estavam nesse Departamento ultramarino vinham de Fonds-des-Nègres e Pemerle, como evidenciado no capítulo três da minha tese de doutorado (Joseph, 2015a). Por isso, decidi seguir os rumos da pesquisa nessas localidades haitianas para compreender a lógica e os circuitos da mobilidade, através das dinâmicas das casas e das relações familiares das pessoas conhecidas em Cayenne e, também, no Brasil.

Como evidenciado por Didier Fassin, "O final do século XX e o início do século XXI são, sem dúvida, marcados pela exacerbação das tensões globais expressas através de crescentes restrições de mobilidade humana" (Fassin, 2011, p. 216). Assim, a metodologia etnográfica em mobilidade exige do pesquisador um saber circular ou estar em mobilidade tal como os interlocutores. Segundo Marcus (2001), uma das grandes questões desta forma de se fazer etnografia está nos limites da investigação, nas quais o pesquisador questiona se está construindo o método de acordo com a proposta de campo a qual se propõe, pelo fato deste compreender mais de um local ao mesmo tempo e do pesquisador estar em mobilidade.

A etnografia em mobilidade é crucial para a compreensão dos fenômenos móveis, ou seja, das experiências de mobilidade das pessoas em um contexto no qual o próprio território de conexão está em plena mobilidade. Esta etnografia está caracterizada por múltiplos engajamentos no campo, permitindo-me seguir e reconstituir a circulação das pessoas, as famílias e as casas, além dos objetos e das narrativas. Privilegiei os pontos de vista dos meus interlocutores, deixando-os falar. Assim, a confrontação das três etapas da pesquisa em mais de quatros espaços nacionais permite reflexões acerca das categorias diáspora, refugiado e migrante a partir de posições sociais distintas, mas do mesmo mundo social da mobilidade.

\section{Múltiplos engajamentos}

No segundo dia após a minha chegada à Tabatinga para o trabalho de campo, fui ao porto que liga Peru e Brasil, pois é nesse local que chegam as pessoas que saem do Peru para ingressar no Brasil. Depois de um longo período de observação da chegada de aproximadamente 20 haitianos no porto, subi a estrada de chão para alcançar a Avenida Amizade - a principal do município de Tabatinga - com a intenção de ir à praça principal da cidade, mas não sabia onde ela se localizava. A proprietária peruana do restaurante no qual almocei naquele dia, havia-me dito que, para encontrar os haitianos, teria de ir à praça, em frente à Igreja Matriz de Tabatinga.

Subindo pela estrada encontrei três haitianos vindos do porto. Perguntei-lhes em créole: "Ki kote plas la ye?” (Onde fica a praça?), um me respondeu com outra pergunta: "Quando chegou?”, respondi:“'Ontem”. Logo retrucou:"Você está mentindo, então, não 
vou dizer onde fica até falar a verdade". Eu disse em seguida, "Você não me perguntou de onde vim, cheguei ontem de Manaus". Ele respondeu: “Ué, foi, não gostou e voltou?".

Nessa narrativa, é possível observar dois fatos. Para o meu interlocutor não era aceitável, sendo eu haitiano, estar a dois dias no local sem conhecer a praça. Não era uma praça qualquer, era o espaço de sociabilidade haitiana por excelência. Depois da Igreja Divino Espírito Santo, a praça era o segundo lugar mais frequentado por eles, onde se encontravam diariamente. Geralmente, eram levados ao local no seu primeiro dia ou no segundo, era uma $b a z^{7}$.

O outro fato diz respeito à surpresa demonstrada pelo meu interlocutor quando disse que havia chegado de Manaus, porém, na verdade realizei o caminho inverso, o que causava surpresa para alguns. Mas, no desenrolar das conversas, quando me apresentava como antropólogo residente há oito anos no Brasil, na época, esse primeiro impacto de surpresa se transformava numa relação dialógica na qual as pessoas demonstravam muito interesse em conversar comigo, seja para ter informações ou pedir conselhos. No decorrer da conversa, descobri serem eles originários de Ganthier, uma cidade vizinha de Fonds Parisien, a Comuna de origem do meu pai, cidade fronteiriça com a República Dominicana. Um deles havia trabalhado num posto de saúde com minha irmã, nascida e residente em Fonds Parisien, atualmente em Nova Jersey, nos Estados Unidos. Naquele dia, desisti de ir à praça para acompanhá-los ao lugar onde se alojavam, numa casa alugada na qual havia somente pessoas de Ganthier.

Essas descrições podem parecer longas, mas são importantes para compreender os diferentes níveis da minha relação com os interlocutores, as trocas constituídas e os meus envolvimentos em campo a partir dos múltiplos engajamentos intrinsecamente relacionados com a dimensão multilocal da pesquisa. Esse processo é fruto da observação participante que derivou em uma participação observante (Bourdieu, 1991, 1993, 2003).

O papel desempenhado como antropólogo, sendo haitiano residente há mais de dez anos no Brasil e, portanto, um diáspora para os haitianos; mais o fato de ter residido em vários países antes de vir para o Brasil e conhecer outros, sendo, na época, professor

"Baz é um lugar de pertencimento e de proteção, um espaço de sociabilidade [...], ao mesmo tempo um espaço concreto localizado no território e um espaço moral mais ou menos abstrato, cujas fronteiras e escalas são, como já vimos, móveis e maleáveis" (Neiburg; Nicaise; Braum, 2011, p. 26). Pedro Braum, na sua tese de doutorado sobre "Rat pa kaka: política, desenvolvimento e violência no coração de Porto Príncipe" (2014), mostra que a palavra baz fazia parte do vocabulário da maioria das pessoas com as quais ele conversava no bairro Bel Air, em Port-au-Prince. Segundo ele, era utilizada para fazer referência "às formas diversas de associação comunitária, a uma turma de amigos ou a uma organização política local (como na frase "nós somos base Grand Black", nou se baz gran black); ao território com o qual elas mantinham vínculos, como uma rua, um corredor, um bairro, uma sede, uma casa, um conjunto de casas ou um espaço de sociabilidade (como na frase "aqui é nossa base", la se baz nou); a uma gangue ou grupo armado (como na frase "a base é perigosa", baz la se danjere); ou simplesmente, como forma de demonstração de afeto ou de cumplicidade entre duas pessoas ou mais (como na frase "Como você está minha base?", sak pase baz mwen?)" (Braum, 2014, p. 9) 
da Universidade Federal de Pelotas ${ }^{8}$ e, posteriormente, Presidente da Associação dos Imigrantes Haitianos no Brasil (AIHB); além de visto como um ex-Frei Franciscano Capuchinho 9 pelos membros do Serviço da Pastoral do Migrante e da Mobilidade Humana (incluindo os Padres e Irmãs da Igreja Católica), tendo um tio residido na Guiana Francesa, sendo funcionário do Consulado do Suriname em Cayenne e, finalmente, ter eu encontrado em Tabatinga ex-colegas meus e da minha irmã, tudo isso contribuiu para a minha inserção em campo. Tais dimensões são intrínsecas ao processo de construção do objeto de pesquisa e, posteriormente, à interpretação dos discursos sociais embutidos nessas experiências. Enfim, a minha trajetória permitiu-me olhar o universo investigado de maneira singular.

Por isso, acredito que o trabalho de campo se desenvolveu, fluiu e se materializou enquanto tal pelas condições mencionadas, além do conhecimento das línguas utilizadas na minha interação com os diferentes sujeitos e agentes da pesquisa. Certamente, se não tivesse tais conhecimentos, experiências, características ou condições, este trabalho não teria tomado tal rumo, seria outra investigação.

Participar da fundação da Associação dos Imigrantes Haitianos no Brasil - AIHB também foi fundamental para a maneira como lidei com a prática etnográfica, a partir de um intenso envolvimento intersubjetivo. Por meio da Associação, tive a oportunidade de ouvir histórias fantásticas que talvez não fosse possível serem ditas numa entrevista na condição de antropólogo. Mantenho, também, a minha atuação ativa junto à AIHB, ajudo com informações relativas às questões migratórias, no tangente ao jurídico, oferta de trabalho e sobre a configuração da presença haitiana no Brasi ${ }^{10}$.

Essa atuação tem sido amplificada através do comprometimento no cenário nacional, pois, em março de 2014, a AIHB organizou uma etapa preparatória da $1^{\text {a }}$

8 Nessa época eu era professor do Curso de Licenciatura em Educação do Campo (CLEC) e Coordenador do Curso de Educação para as Relações Étnicorraciais (ETRC) da Universidade Federal de Pelotas (UFPel) em parceria com a Secretaria de Educação Continuada, Alfabetização, Diversidade e Inclusão (SECADI).

9 Quando Frei (religioso católico), eu pertencia à Vice Província da Ordem dos Franciscanos Capuchinhos na República Dominicana. Ela é uma Congregação Religiosa Católica. Na minha época, ela não existia ainda no Haiti, assim realizei os primeiros anos de formação na República Dominicana e depois, o noviciado na América Central, em Honduras. Nessa etapa de formação, tive a oportunidade de desenvolver atividades pastorais na Casa de Acolhida dos migrantes na cidade de Ocotepeque, na qual recebiam pessoas que viajavam ao México para alcançar os Estados Unidos.

10 Federico Neiburg (2017), no seu recente texto sobre a relação entre etnógrafos e seus públicos no contexto da etnografia coletiva no Haiti e no Brasil, ao mostrar o engajamento em campo da equipe de pesquisa do Núcleo de Economia e Cultura (NUCEC)/Museu Nacional-UFRJ, do qual faço parte, o autor chama a atenção que não se trata de uma campanha ao engajamento do etnógrafo em campo, mas de reconhecer a observação participante e o engajamento como parte da prática etnográfica, baseando-se nas relações estabelecidas com as pessoas na sua alteridade. Estes últimos são pessoas ligadas a outras que formam - no domínio da investigação em si e também através da interlocução com nós mesmos - públicos e sujeitos etnográficos. 
Conferência Nacional sobre Migração e Refúgio (COMIGRAR) no Brasi1 ${ }^{11}$, da qual consequentemente participei como delegado na etapa nacional, em maio do mesmo ano em São Paulo. Dela resultou um novo Anteprojeto da Lei de Migrações e Promoção dos Direitos dos Migrantes no Brasil, que pretendia reestruturar a atual lei migratória no país, criada há mais de 30 anos no contexto da ditadura militar ${ }^{12}$.

Dentre outros fatos marcantes de minha vivência em campo, um muito especial aconteceu quando andava pela Avenida da Amizade, em Tabatinga, e encontrei Steeve, que me abordou para narrar a sua história e pedir conselhos. $\mathrm{Na}$ época, ele com 24 anos, chegado à Tabatinga em janeiro de 2012, contou-me ter-se casado em 2010 com uma moça em Port-au-Prince. Um dia, depois do trabalho, não encontrou a esposa em casa. Entrou em contato com a família dela e disseram não terem notícias da moça. Depois de um mês, recebeu uma ligação dela dizendo estar em Tabatinga. A sua família havia organizado a viagem, realizada junto com seu irmão de 26 anos que também conheci em Tabatinga ${ }^{13}$.

Pelo telefone, ela dissera ao Steeve estar arrependida. Pedira para ele vender os móveis da casa, repassara as informações dos trajetos para realizar a viagem, passando por Santo Domingo com escala em Panamá, até chegar ao Peru para alcançá-la na referida fronteira. Sem ajuda de agenciadores, Steeve fizera exatamente como a esposa lhe havia traçado os caminhos. Estando em Tabatinga com ela, sofria bastante, porque percebia que a esposa de 23 anos havia mudado completamente na relação com ele. No dia anterior, quando Steeve me abordou para conversar, contou-me que, durante uma briga com a esposa, ela se cortara com uma gilete e o ameaçara de chamar a polícia. Nessa ocasião, abalado com a conjuntura, Steeve queria o meu conselho.

Como evidenciado nessa narrativa do Steeve, durante a pesquisa de campo um dos instrumentos etnográficos mais preciosos foi ouvir os meus interlocutores. Tal dimensão de "escuta e atenção" exige do pesquisador, além da abertura ao outro, tendo a disponibilidade de ouvi-lo não somente como fornecedor de dados e contador de suas peripécias da vida cotidiana, mas também com a capacidade de ajudá-lo na singularidade de seu caso particular, afinal, é o que ele espera. Nesse contexto, a categoria "ajuda" é

11 O objetivo da $1^{\text {a }}$ COMIGRAR foi reunir migrantes, refugiados, profissionais envolvidos na temática migratória, estudiosos, servidores públicos, representações diversas que vivenciam a realidade da migração, para uma reflexão e aporte coletivos de insumos para a Política e do Plano Nacionais de Migrações e Refúgio (Manual Metodológico $1^{\text {a }}$ Comigrar, 2014).

12 Em 18 de abril de 2017, a nova Lei de Migração (Lei 13.445/2017), de autoria do Senador Aloysio Nunes (PSDB-SP), foi aprovada pelo plenário do Senado Federal, e no dia 25 de maio do mesmo ano, a mesma foi sancionada com vetos pelo Presidente Michel Temer. Apesar dos vetos, essa nova Lei é considerada um avanço comparando com o atual Estatuto do Estrangeiro. Disponível em: $<$ http://migramundo.com/nova-lei-de-migracao-e-sancionada-mas-vetos-derrubam-anistia-e-mais-19-pontos/>. Acesso em: 15 jun. 2017.

13 Para pensar as relações de gênero e de conflitos e violências interpessoais no Haiti, de homens contra mulheres e vice-versa, notadamente no nível de intimidade conjugal, ver o relatório de Pedro Braum, Flávia Dalmaso e Federico Neiburg (2014) sobre "Gender issues: relations between men and women in the low-income districts of Port-au-Prince". 
central na relação com os meus interlocutores. No caso de Steeve, naquele momento, precisava de alguém que lhe emprestasse o ouvido, entendesse sua linguagem e sofrimento social, seus sentimentos e pensamentos.

Abdelmalek Sayad trata dessas últimas dimensões, na medida em que mostra em La misère du monde (1993) as relações conflituosas entre duas famílias vizinhas residentes na periferia de Paris. Elas produzem três tipos de discursos: o primeiro, da família Ben Miloud de imigrantes, o pai nascido no sul da Argélia, tendo chegado pela primeira vez no ano de 1949 à França. Seu discurso retrata a história residencial da família durante todo o seu processo migratório. Depois, há o discurso coletivo dos seus filhos, nascidos na França, tratando da situação atual em que a família vive; e o terceiro é o discurso da vizinha francesa chamada Menier, que odiava o comportamento e os barulhos provocados pelos filhos de Ben Miloud. Sayad mostra como os três tipos de discurso precisavam ser ouvidos - por ele como pesquisador - para "compreender os pontos de vistas divergentes produzidos a partir de posições sociais distintas, mas da mesma realidade social" (Sayad, 1993, p. 52). Como diria Roberto Cardoso de Oliveira: "O ouvir ganha em qualidade e altera uma relação, qual estrada de mão única, em uma outra de mão dupla, portanto, uma verdadeira interação" (2006, p. 24).

Como Steeve e Henri, muitos dos meus interlocutores quando me encontravam num restaurante, na rua, num supermercado, me narravam suas experiências cotidianas e vida íntima, talvez difíceis de serem obtidas por meio de uma entrevista formal. Esse diálogo com Steeve serviu também para eu ficar atento à relação entre casais, notadamente ao papel deles na trajetória dos candidatos à viagem, participando no processo ou não.

No entanto, há de ponderar-se: alguns me olhavam com desconfiança, achando ser eu jornalista ou trabalhar para algum órgão do Governo brasileiro. Do ponto de vista dos interlocutores, eles evitavam as conversas com os jornalistas porque estes usavam as informações e fotos para reforçar estigmas e estereótipos associados ao Haiti e à sua população, ressaltando a miséria, a violência e as doenças. Não queriam ser ligados a tais imagens e representações, sobretudo pelo receio de os familiares no Haiti saberem das situações precárias nas quais viviam no Brasil.

O trabalho não focaliza a minha própria trajetória como migrante, mas tais dados são importantes no desenvolvimento da investigação e valorizadas na análise, podendo revelar os diferentes lugares, as posições de onde falo e a minha postura analítica, abrindo conversas com interlocutores e propiciando um tipo singular de intercompreensão. Aqui o conceito de noção de posição remete a maneira de me colocar no campo, não somente no sentido de me situar e demarcar as minhas posições, mas também, de dar sentido a elas.A ideia de postura faz referência a uma abordagem global quando há uma perspectiva epistemológica a adotar, controlando, ao mesmo tempo, a investigação empírica e a construção do texto, resultante da pesquisa.

Nesse sentido, concordo com Pierre Bourdieu, quando afirma: 
Todo o comportamento do pesquisador, sua maneira de se apresentar e de apresentar a pesquisa, suas questões e seus silêncios, os reforços ou os incentivos que ele dá através de gestos ou a fala são tanto indicações e de intervenções próprias para orientar os discursos do pesquisado e a estruturálos (Bourdieu, 1991, p. 3).

Aproveitei essa posição de múltiplos pertencimentos e engajamentos para desenvolver o trabalho de campo e a análise do material etnográfico. Ao mesmo tempo, durante a pesquisa de campo, a análise do material e a produção da escrita do trabalho, procurei manter uma aproximação crítica (Santos, 1994) para melhor compreender e analisar o sentido social da mobilidade, as trajetórias individuais e coletivas dos sujeitos da pesquisa e a maneira pela qual se articula as categorias diáspora, refugiado e migrante no espaço (trans)nacional haitiano e transfronteiriço. Mas, a ambiguidade da minha situação e o entendimento como pesquisador estiveram sempre presentes.

Tenho plena consciência de as posições e as posturas terem influenciado as observações e as análises das diferentes escalas deste trabalho. Também estou cônscio de meu pertencimento ambivalente ter influenciado a percepção dos meus interlocutores. No entanto, procurei fazer valer a proposta de Bourdieu a respeito da objetivação participante que pretende explorar "não a 'experiência vivida' do sujeito conhecido, mas as condições sociais de possibilidade (as implicações e os limites) dessa experiência, notadamente, do ato de objetivação" (2003, p. 44). O mesmo autor continua seu argumento e afirma:

O que deve ser objetivado não é o antropólogo fazendo a análise antropológica de um universo estrangeiro, mas o mundo social que faz do antropólogo e da antropologia consciente ou inconsciente que ele engaja na sua prática antropológica. Não é somente o seu meio de origem, sua posição e sua trajetória no espaço social, seu pertencimento e suas adesões sociais e religiosas, sua idade, seu sexo, sua nacionalidade, etc, mas também, e sobretudo, sua posição particular no microcosmo dos antropólogos (Bourdieu, 2003, p. 44-45).

Como os meus interlocutores - e deve ter sido observado neste texto - sou de uma família espalhada pelo mundo, tendo avós, avôs (in memoriam), tios, tias, primos, primas que moram ou já moraram nos Estados Unidos, França, Canadá e outras partes do Caribe por muitos anos, alguns durante décadas; tios maternos que nasceram em Brooklyn e nunca foram para o Haiti; primos nascidos em Miami, falecidos e enterrados por lá. Pode parecer extensa toda essa descrição, mas é importante para entender quanto as minhas experiências estão relacionadas a este trabalho de pesquisa.

Parafraseando Bourdieu (1991, p. 5), como antropólogo eu não poderia ignorar que "o meu próprio ponto de vista é um ponto de vista de um ponto de vista" ou, segundo Clifford Geertz (2008 [1973]), a minha própria construção é uma construção das construções de outras pessoas. São esses múltiplos engajamentos em campo que contribuíram para a compreensão, a proximidade crítica e a análise dos múltiplos pontos de vista, por vezes diferentes. Essa dimensão analítica ajudou-me a problematizar qualquer condição de possibilidade de "um ponto de vista único, central, dominante [...] em 
beneficio da pluralidade das perspectivas correspondentes à pluralidade dos pontos de vista coexistentes e, às vezes, diretamente concorrentes" (Bourdieu, 1993, p. 14). Desta forma, foi importante objetivar, no sentido bourdieusiano (2003), a mim mesmo enquanto pesquisador, para praticar a etnografia "de dentro", em sua interioridade, assim, decifrando e descrevendo, com densidade, os discursos sociais de um universo em mobilidade.

\section{Considerações finais}

Ao longo do artigo, discuto os usos das categorias "burocráticas", "estatais" e pragmáticas de diáspora, refugiado e migrante, lançando luz sobre estratégias dos sujeitos em mobilidade e problematizando noções como origem e destino/emigrante e imigrante, que tendem a "fixar" os diversos movimentos e trajetórias destes sujeitos.

Enfatizei a necessidade de adotar uma perspectiva etnográfica em mobilidade e múltiplos engajamentos para explorar situações múltiplas em espaços sociais diferentes, seguindo as pessoas, acompanhando as experiências vividas e descrevendo a trajetória de vida delas.A partir da pergunta: Qual o significado de ser diáspora, refugiado, migrante para as pessoas que são realmente consideradas como tais? Ofereço algumas chaves analíticas para termos uma compreensão nuançada dos sentidos sociais dessas três categorias do ponto de vista dos próprios sujeitos em mobilidade.

Como já disse, o conceito diáspora serve para qualificar pessoas, ações, dinheiro, objetos e casas. No universo haitiano, a pessoa diáspora ocupa um lugar privilegiado. Narrei na trajetória de Henri, que desde a sua adolescência sonhava migrar a Miami para ser diáspora. No início do texto, mostrei que boa parte dos interlocutores haitianos chegados à fronteira Brasil, Colômbia e Peru, não queria ser qualificado de refugiado pela sua conotação pejorativa associada aos boat people, a exceção daqueles que se autodesignavam como tal enquanto estratégia burocrática para regularizar a situação jurídica no país.

No universo haitiano, diáspora e refugiado não são categorias antagônicas, elas participam do mesmo mundo social. Ao mesmo tempo, é o migrante haitiano residente no exterior, por sua vez, quando volta ao Haiti, que é designado como diáspora. É em termos dessas construções pragmáticas, que diáspora, refugiado e migrante são mobilizadas como estratégias individuais e coletivas, constituindo fronteiras morais e sociais através dos discursos das próprias pessoas em mobilidade. As experiências desses sujeitos abrem janelas para refletir sobre a gramática da circulação, iluminando e contribuindo para aprimorar as ferramentas metodológicas e as teorias em estudos migratórios.

\section{Referências}

BOURDIEU, Pierre. Introduction à la socioanalyse. In: Actes de la recherche en sciences sociales, v. 90, décembre, p. 3-5, 1991.

La Maison ou le monde renversé. In: BOURDIEU, Pierre. Le sens pratique. Paris: Éditions de Minuits, 
. L'illusion biographique. In: Actes de la recherche en sciences sociales. v. 62-63, juin, p. 69-72, 1986.

(Org). L'espace des points de vue. In: BOURDIEU, Pierre. La misère du monde. Paris: Éditions du Seuil, 1993.

L'objectivation participante. In: Actes de la recherche en sciences en sociales, v. 150, décembre, p. 43-58, 2003.

CONSELHO SUPERIOR DA JUSTIÇA DO TRABALHO (Brasil). Resolução n. 97/CSJT, de 23 de março de 2012. Diário Eletrônico da Justiça do Trabalho, Brasília, DF, n. 947, 27 mar. 2012. Caderno Jurídico do Conselho Superior da Justiça do Trabalho, p. 1-4.

BRAUM, Pedro. Rat pa kaka: Política, desenvolvimento e violência no coração de Porto Príncipe. 2014. 462f. Tese (Doutorado em Antropologia Social) - Museu Nacional, Universidade Federal do Rio de Janeiro, Rio de Janeiro, 2014.

BRAUM, Pedro; DALMASO, Flávia; NEIBURG, Federico. Gender issues: Relations between men and women in the low-income districts of Port-au-Prince. Rio de Janeiro:Viva Rio, Nucec/UFRJ, 2014. Disponível em: <http://www.nucec.net/publicaccedilotildees-selecionadas.html>. Acesso em: 08 jun. 2016.

BÜSCHER, Monika; URRY, John; WITCHGER, Katian. Mobile methods. New York: Routledge, 2011.

DORAII, Kamel et al. (Ed.). Bilan des travaux sur la circulation migratoire. Poitiers: Ministère de la Solidarité et de l'Emploi, Migrinter, 1998.

FASSIN, Didier. Policing Borders, producing boundaries the governmentality of immigration in dark times. Annu. Rev. Anthropol, v. 40, p. 213-226, 2011.

FOUCAULT, Michel. Segurança, território e população. Curso dado no Collège de France (1977-1978). São Paulo: Martins Fontes, 2008.

GEERTZ, Clifford. Uma Descrição Densa: Por uma Teoria Interpretativa da Cultura. In: GEERTZ, Clifford. $A$ interpretação da cultura. 1. ed. Rio de Janeiro: LTC, 2008. [1973].

JOSEPH, Handerson. Diaspora. As dinâmicas da mobilidade haitiana no Brasil, no Suriname e na Guiana Francesa. 2015. 429f. Tese (Doutorado em Antropologia Social) - Museu Nacional, Universidade Federal do Rio de Janeiro, Rio de Janeiro, 2015a.

Diaspora. Sentidos sociais e mobilidades haitianas. Horizontes Antropológicos, Porto Alegre, ano 21, n. 43, jun., p. 51-78, 2015b.

As relações de gênero, de classe e de raça: mulheres migrantes haitianas na França e no Brasil. Revista de Estudos e Pesquisas sobre as Américas, Brasília, v. 9, n. 2, p.1-33, 2015c.

.. Diaspora, circulation et mobilité: Les jeunes haïtiens au Brésil. In: MARCELIN, Louis Herns; CELA, Toni; DORVIL, Henri (Org.). Les jeunes haïtiens dans les Amériques // Haitian Youth in the Americas. Montréal: Presses de l'Université du Québec (PUQ), 2017a.

.. Diáspora. In: NEIBURG, Federico (Org). Conversas etnográficas haitianas. Rio de Janeiro: Papéis Selvagens Edições, 2017b.

Mobilité transfrontalière haïtienne au Brésil: Kongo, vyewo et dyaspora. Recherches Haïtiano-Antillaises, L'Harmattan, 2017c.

MANUAL METODOLÓGICO - COMIGRAR. $1^{a}$ Conferência Nacional Sobre Migrações e Refúgio, maio de 2014, São Paulo, Brasil. Disponível em: <http://www.participa.br/articles/public/0006/4010/Manual_ COMIGRAR_Janeiro\%202014____.pdf>.

MA MUNG, Emmanuel. Dispositif économique et ressources spatiales: éléments d'une économie de diaspora. Revue européenne des Migrations Internationales, v. 8, n. 3, p. 175-193, 1992.

MARCUS, George E. Ethnography in/of the World System:The Emergence of Multi-Sited Ethnography. Annu. Rev. Anthropol, v. 24, p. 95-117, 1995.

Etnografia en/del Sistema mundo. El surgimiento de la etnografía multilocal. Alteridades, v. 11, n. 22, p. 111-127, 2001. 
NEIBURG, Federico. A true coin of their dreams. Imaginary monies in Haiti. HAU: Journal of Ethnographic Theory, v. 6, n. 1, p. 75-93, 2016.

Serendipitous Involvement: Making Peace in the Geto. In: FASSIN, Didier (Ed). If truth be told: the politics of public ethnography. Durham: Duke University Press, 2017. p. 170-198.

NEIBUR G, Federico; NICAISE, Natacha;BRAUM, Pedro. Lideranças em Bel Air. Relatório de pesquisa. Programa de Pós-Graduação em Antropologia Social, Núcleo de Pesquisas em Cultura e Economia (NUCEC), Museu Nacional, Universidade Federal do Rio de Janeiro, set. 2011.

OLIVEIRA, Roberto Oliveira de. O trabalho do antropólogo. 3. ed. São Paulo: Paralelo 15, 2006.

OLWIG, Karen Fog. Caribbean Journeys. An ethnography of migration and home in three Family networks. Durham: Londres: Duke University Press, 2007.

PIMENTEL, Marília; COTINGUIBA, Geraldo Castro. Wout, raketè, fwontyè, anpil mizè: reflexões sobre os limites da alteridade em relação à imigração haitiana para o Brasil. Universitas Relações Internacionais, Brasília, v. 12 , n. 1, p. 73-86, jan./jun. 2014.

SANTOS, Boaventura de Souza. Pela mão de Alice: O social e o político na pós-modernidade. 3. ed. Porto: Edições Afrontamento, 1994.

SAYAD, Abdelmalek. A imigração ou os paradoxos da alteridade. São Paulo: Edusp, 1998.

Une famille déplacée. In: BOURDIEU, Pierre (Ed.). La misère du monde. Paris: Éditions du Seuil, 1993.

SIMON, Gildas. Réflexion sur la notion de champ migratoire international. Hommes et Terres du Nord. Acte du coloque international Migrations Internes et Externes en Europe Occidentale. Lille, 16, 17, 18 octobre 1980, numéro spécial, tome 1, 1981.

. Une Europe communautaire de moins en moins mobile?. Revue Européenne des Migrations Internationales, v. 8, n. hors série, Poitiers, p. 67-89, 1992.

TARRIUS, Alain. Les nouveaux cosmopolitismes. Mobilités, identités, territoires. Édition de l'Aube, 2000.

VIEIRA, Rosa. Itinerâncias e governo: a mobilidade haitiana no Brasil. 2014. 152f. Dissertação (Mestrado em Sociologia e Antropologia) - Universidade Federal do Rio de Janeiro, Rio de Janeiro, 2014.

. O governo da mobilidade haitiana. Mana, Rio de Janeiro, n. 23, v. 1, p. 229-254, 2017.

\section{Entrevistas}

Henri, maio de 2013. 


\title{
Diaspora, refugee, migrant: ethnographic perspective on mobility and cross-border
}

\begin{abstract}
This article proposes from the ethnographic experience in mobility and multiple engagements of the field researcher a discussion about the way in which the diaspora, migrant and refugee categories are mutually constituted in the Haitian social world. So what are the social and pragmatic meanings attributed by Haitians to the categories of diaspora, refugee and migrant? In what way, mobility becomes a key concept to think about the dynamics of diaspora, refugee and migrant being in the (trans)national and (trans)border space ?.The focus is the contingent of Haitians coming to Brazil through the border Brazil, Colombia and Peru, from 2010 to 2013 and those who went to Suriname and French Guiana in the same period. Ethnographic research is based on this frontier, but it also conducted in Manaus (Brazil), Cayenne (French Guiana), Paramaribo (Suriname) and Fonds-des-Nègres and Pemerle (Haiti).
\end{abstract}

Keywords: Diaspora, refugee, migrant, ethnography in mobility, (trans)border.

\section{Diáspora, refugiado, migrante: perspectiva etnográfica en movimiento $y$ transfronteriza}

\section{Resumen}

Este artículo propone una discusión sobre la forma como las categorías diáspora, migrante y refugiado se constituyen mutuamente en el mundo social haitiano, a partir de la experiencia etnográfica en movimiento y múltiples compromisos del investigador en campo. Se pregunta entonces: ¿cuáles son los sentidos sociales y pragmáticos atribuidos por los haitianos a las categorías diáspora, refugiado y migrante? ¿De qué modo el movimiento se convierte en un concepto clave para pensar las dinámicas del ser diáspora, refugiado y migrante en el espacio (trans)nacional y (trans)fronterizo? El foco es el contingente de haitianos venidos a Brasil por la frontera entre Brasil, Colombia y Perú de 2010 a 2013 y los que fueron para Surinam y la Guayana Francesa en ese mismo período. La investigación etnográfica se articula a partir de la referida frontera; sin embargo, pero también se desarrolla en Manaus (Brasil), en Cayena (Guayana Francesa), Paramaribo (Surinam) y Fonds-des-Nègres y Pemerle (Haití).

Palabras claves: Diáspora, refugiado, migrante, etnografia en movimiento, (trans)fronterizo. 